\section{Evolution of the Function of the Cerebellum and Cerebral Hemispheres}

A. I. Karamyan. Translated from the Russian. Pp. I6I, illustrated. Jerusalem: Israel Program for Scientific Translations. 1962. 42s.

This book is a translation from the Russian and denotes its origin by the strong Pavlovian influence apparent throughout its pages. The book is concerned with the comparative physiology of the cerebellum and cerebral hemispheres in a number of species. In fish, conditioned reflexes to light and sound were readily formed. On removal of the cerebellum these reflexes could not be re-learned, whereas removal of the forebrain, in which the pallium is hardly developed in fish, had no effect. The amphibian provided a striking contrast. Conditioned reflexes were harder to form, removal of the cerebellum had no effect, whereas removal of the fore-brain destroyed such reflexes as had been formed and they could be re-learned only with difficulty. By the time the pigeon was reached, removal of the cerebellum had no effect upon prelearned reflexes, and allowed the subsequent formation of new conditioned reflexes. The explanations of these findings are discussed and especially the inter-relationship between the cerebellum and cerebrum as we move progressively through the animal scale.

\section{Obstetrics and Gynæcology Combined for Students}

Elliot E. Philipp. Pp. xii + 599, illustrated. London: H. K. Lewis. 1962. fo 15 s.

Welcome to a neonate in the nursery of obstetrical and gynæcological textbooks! It is an unusual child, in fact a conjoined twin. This is not due to a malevolent act of fate, but is the reasonably successful result of careful planning. Mr. Elliot Philipp has written a combined obstetrical and gynæcological guide for students, from which the publishers have produced an attractive book. It is certain to be popular.

In an excellent terminal chapter on 'Law in Relationship to Obstetrics and Gynæcology' (Chapter 13, for those unlucky enough to be involved in legal proceedings) the author ends the book with two rules for medical witnesses and examination candidates. They are:

(I) Speak slowly, clearly and in simple language, avoiding all jargon.

(2) Do no rush at an answer, but think before speaking.

It is apparent that he himself followed these rules in preparing this book. He admits it was designed for the average, rather than the brilliant student and clear guidance is offered on how to use textbooks to best advantage. The student who chooses this one for his library must have access to other textbooks, for it was not possible in a volume of this size to combine and cover adequately the usual contents of a major work on both obstetrics and gynæcology. None the less, Mr. Philipp has succeeded in condensing sufficient material to make this a very useful introductory guide.

Some of the instruction is more traditional than accurate. For example: 'Accidental hæmorrhage occurs as a direct result of a toxæmic process'; 'Carcinoma of the corpus seldom, if ever, spreads into the pelvic glands'; 'Sarcomatous degeneration in a fibroid has an absolutely hopeless prognosis'; 'Hyperemesis gravidarum is the common condition of morning sickness'; 'If insufflation and salpinography give the same results the patient can be informed with reasonable certaint that the tubes are or are not patent'.

There are some surprising omissions. Failure tबे inspect the cervix, when a patient with a suspecteo placenta prævia is treated conservatively, can result in. carcinoma being overlooked for many weeks. Sensi $\overrightarrow{\vec{*}}$ tivity tests should be made before finalizing treatment? for genital tuberculosis. The student who is taught to give Ergometrine with the crowning of the head shoulds know the dangers of shoulder dystocia. When details are given of laboratory tests, without critical assessmente of the accuracy of these tests, the common mistake cap be perpetuated of regarding ancillary aids to diagnosio as being practically infallible. The absence of references to at least a selection of original papers will be regretted by keener students.

A few inaccurate statements require attention in the next edition. Flying Squads were not introduced 22 ? years ago in Birmingham or even in Newcastle. Colog poscopy is not a relatively new technique. The excellen results of the Crown Street obstetricians in reducing. the incidence of eclampsia have not been refuted by thee University College Hospital team.

In spite of these criticisms this is an interesting an welcome edition. It will grow in wisdom and ing stature.

\section{Modern Trends in Surgery}

Vol. I. Editor: W. T. IRvine, B.SC., M.D., CH.M.

F.R.C.S., F.R.C.S.E. Pp. vii +307 , illustrated $\underset{\mathbb{D}}{\mathbb{D}}$

London: Butterworths. 1962. 63s.

- Professor Irvine is to be congratulated on editiwgD this book which is an excellent addition to the ModefnTrends series. There are 18 contributors, each ones being an expert in his own particular branch of surgey No attempt has. been made to cover all aspects $\$ \Phi$ general surgery, but only those where the greatesto recent advances have taken place. Each chapter is complete on its own subject and at the end of each chapter there is an excellent bibliography. The sub-n jects covered range from the problems of gastric surgeryo to the complications associated with massive blood $\mathcal{Q}$ transfusions.

Amongst I4 different chapters there is an interesting one on renal artery stenosis, well illustrated with excel lent radiographs, and a further chapter on renal trans plantation, a subject which will interest many surgeons? Organ transplantation, not only of the kidney, is goingo to be in the forefront of surgical advances during the next five years.

Hypothermia and vascular surgery are well presented 3 but a rather pessimistic view is taken of surgery for coronary atherosclerosis, and no reference is made too the work of Sabiston who reported excellent results in admittedly a small series of cases of coronary endo-o arterectomy.

Two particular important chapters consider methods $\frac{7}{2}$ for the prevention of wound sepsis, and also explain in fairly simple terms the reasons why patients die from electrolyte disturbances. There is a stimulating chaptero on biliary problems, and a further one on surgery off the rectum and anus giving an excellent description and indication for sphincter-saving operations.

This is a compact and easily read book full of up-to-O date information which should be read by all surgeons who wish to keep in touch with modern advances, ande also will be of great help to those preparing for the Fellowship. 